\title{
THREE PORT LAPAROSCOPIC CHOLECYSTECTOMY IN TERTIARY CARE HOSPITAL OF CENTRAL INDIA - AN AUDIT OF 200 PATIENTS
}

Krishnanand ${ }^{1}$, Roshan Chanchlani' ${ }^{2}$, Madhu Chanchlani ${ }^{3}$

\section{HOW TO CITE THIS ARTICLE:}

Krishnanand, Roshan Chanchlani, Madhu Chanchlani. "Three port laparoscopic cholecystectomy in tertiary care hospital of central India - an audit of 200 patients". Journal of Evolution of Medical and Dental Sciences 2013; Vol. 2, Issue 43, October 28; Page: 8290-8296.

ABSTRACT: BACKGROUND: Since 1990 laparoscopic cholecystectomy is the gold standard treatment for symptomatic gall stones disease. The aim of this study was to evaluate the results of three port laparoscopic cholecystectomy in symptomatic patients with gall stones in terms of conversion rate, length of hospital stay, post operative complications, morbidity and mortality. METHODOLOGY: The retrospective study was carried out in Department of Surgery at Chirayu Medical College and Hospital, Bhopal. All the patients who underwent laparoscopic cholecystectomy in the department of surgery from (May2011- April 2013) were reviewed from department records. Patients with co morbidities, altered Liver function test and obstructive jaundice were excluded from the study. Demographics with patient details, conversion to open, complications of anaesthesia and surgery were reviewed from clinical notes, and department register. Data was analysed using SPSS-18 and results were compared with international studies. RESULTS: Out of 200 patients174 were females (87\%) and $26(13 \%)$ males. The mean age of patients was $40.47 \pm 12 y$ rs, the youngest patient was10 yrs old and oldest patient was $80 \mathrm{yr}$ old. Mean operative time was $50 \mathrm{~min} \pm 11.16 \mathrm{~min}$. The conversion rate in our series was 6(3.0\%) cases; Port site wound infection was seen in 6 (3\%) patients. There was no bile duct injury, major haemorrhage or bowel injury necessitating opening surgery. On follow up no patient had post operative abdominal abscess, port site hernia or post operative bile duct stricture, there was no mortality in our study. CONCLUSION: Laparoscopic cholecystectomy with three ports is effective \& safe modality to treat gall stones. Good training careful case selection, initial learning curve, meticulous technique, well trained team and high standard equipments are of paramount importance to ensure good results.

KEY WORDS: Bile duct injury, Cystic duct leak, galls stones, three port laparoscopic cholecystectomy.

INTRODUCTION: The gold standard treatment for symptomatic gall stone is Laparoscopic Cholecystectomy since 1990.1,2 The main advantage of three port Laparoscopic Cholecystectomy is less post operative pain, shorter hospital stay, less intra-abdominal adhesions, quick return to work, decrease postoperative complications and better cosmetic outcome. ${ }^{3}$ The study was performed to evaluate the efficacy of three port Laparoscopic Cholecystectomy in context to its complications, morbidity and mortality.

MATERIAL AND METHOD: This retrospective study was carried out in the department of Surgery, $\mathrm{CMCH}$, Bhopal, after approval by ethical committee. Operative and clinical records of all patients who underwent Laparoscopic Cholecystectomy over 2 years from (May2011- April 2013) were reviewed. All patients of gall stone disease were admitted through outpatient department. Detailed history, clinical examination and investigations such as Complete Blood Count, ESR, Blood sugar, Blood Urea, 
Serum Creatinine, liver function test, HbsAg, HCV antibody, X ray chest, Ultrasound abdomen, especially hepato biliary system including size of Common Bile Duct,ECG, and cardiac assessment were done.

All the symptomatic patients who were clinically and radiologically diagnosed as gall stones were included except those with co morbidities altered liver function tests and obstructive jaundice. In all 200-patients Laparoscopic Cholecystectomy was done using three port techniques by same surgeon. Informed consent was taken from all the patients, also explaining the risk of conversion to open operation.

The three port technique involved inserting a $10 \mathrm{~mm}$ trocar just above the umbilicus using the open (Hasson's) technique through which the videoscope 30 degree was introduced. Another 10 $\mathrm{mm}$ trocar was inserted $3 \mathrm{~cm}$ below the xiphisternum and finally a $5 \mathrm{~mm}$ trocar at the right hypochondrium anterior axillary line $3 \mathrm{~cm}$ below the costal margin (Image no. 1 \& 2). The operating surgeon hold the dissecting instruments with his right hand through the $10 \mathrm{~mm}$ trocar while holding the gall bladder at the infundibulum with a grasper through the $5 \mathrm{~mm}$ trocar moving the infundibulum right and left or back and forth to display Calot's triangle ; blunt dissection was used for adequate display of cystic duct and cystic artery. The cystic duct was then clipped and divided followed by the cystic artery. The gall bladder was then dissected from its bed and extracted from either the umbilical or the sub xiphisternal port.

All patients were followed up every fortnightly for first two months. We reviewed demographics such as age, gender, case conversion to open, intra operative and post operative complications, morbidity and mortality from records. Data was analysed using SPSS-18.

RESULTS: A total of 200 patients underwent three port Laparoscopic Cholecystectomy during the study period out of it 174 were females (87\%), 26 were males (13\%). Mean age of patients was $40.47 \pm 12$ yrs. youngest patient was 10 years old (Figure no.1). The indications of surgery were symptomatic cholelithiasis in 153 (76.5\%), chronic cholecystitis 32 (16\%), acute cholecystitis$12(6 \%)$, mucocele of gall bladder 2 patients (1\%), polyp of gall bladder $1(0.5 \%)$ (Table no. 1 ).

As per the American society of anaesthesia classification ASA1- 60(30\%), ASA2 - 106 (53\%), ASA3-34 (17\%) (Table no. 2). All patients were operated under general anesthesia. Mean operation time was $50 \mathrm{~min} \pm 11.16 \mathrm{~min}$.

The conversion rate to open in our series is $6(3.0 \%)$ cases. The reason of conversion was difficult dissection in calots triangle in 4 patients and adhesions and obscure anatomy at porta hepatitis in 2 patients.

Post operatively Ryles tube was removed in most of the patients on $1^{\text {st }}$ day. Post operative hospital stay in uncomplicated cases was 1-2 days and in complicated cases it was 5-6 days mean (range) is $2.2 \pm 0.6$ with return to work in 7 days. $6(3 \%)$ patients developed superficial surgical site infection. 1 case $(0.5 \%)$ had bile leak from cystic stump. There was no Common Bile Duct injury, haemorrhage, or bowel injury necessitating conversion to open.

On follow up no patient developed post operative abscess, port site hernia or post operative bile duct stricture. 2 patients (1\%) were diagnosed preoperatively as choledocholithiasis by deranged Liver Function Tests and imaging, they were treated by ERCP and after stone clearance from Common Bile Duct, these patients underwent laparoscopic cholecystectomy later in following week. In spite of ASA 3 in 17\% cases only $1 \%$ were kept in ICU for 2 days for post operative 
monitoring. There was no other anaesthesia complication, mortality or morbidity. There was no mortality in our series.

DISCUSSION: Gallstone disease is a global health problem. The incidence is $10-20 \%$ of the whole adult population, making laparoscopic cholecystectomy one of the most frequently performed operations in the world. ${ }^{4}$ Most patients are asymptomatic and gallstones are generally detected with ultrasonography during the evaluation of unrelated medical conditions. Over the past two decades, Laparoscopic Cholecystectomy has become the gold standard for the surgical treatment of gallbladder disease. A shorter hospital stay and thus a more rapid return to normal activity and work, less postoperative pain, a faster recovery, and lower cost and better cosmesis are some of the advantages of Laparoscopic Cholecystectomy over open surgery.5,6 During dissection of cystic artery and cystic duct it is easier and safer than conventional method mostly in obese patient undergoing surgery.

In developed countries less than $20 \%$ of the total cholecystectomies are performed by open method but in India, open procedure is still common because of scarcity of skill and apparatus. Though laparoscopic surgery is being adopted quickly in our country but training programmes are still limited. Unfortunately, despite the numerous advantages of the method, it is estimated that the incidence of iatrogenic bile duct injury has increased from $0.1-0.2 \%$ to $0.4-0.6 \% .^{7}$ We have started laparoscopic surgery in a newly established setup with an aim of providing a very high standard of care that should be comparable to international standards. We believe with our experience during a learning curve that minimal invasive technique demands extensive surgical training especially hand, eye and foot coordination and depth perception. Majority of the patients in our study were women which is consistent with national and international studies. ${ }^{8}$ Our study showed a conversion rate of $3.0 \%$ which compares favourably with the rates reported in the literature. According to published studies in recent years, the conversion rates vary widely (range: $2.6-7.7 \%$ )..$^{9}$ The conversion from Laparoscopic Cholecystectomy to open cholecystectomy results in a significant change in outcome for the patient because of the higher rate of postoperative complications and the longer hospital stay. ${ }^{10}$ The conversion rate as well as complications associated with Laparoscopic Cholecystectomy depend on the experience of the surgeon and the degree of difficulty faced during surgery, which can be affected by factors such as a history of previous abdominal surgery, recurrent attacks of cholecystitis, acute cholecystitis (AC), advanced age of the patient, or male gender. ${ }^{11}$ The other reasons reported in the literature are haemorrhage in Calot's triangle, slipped clips, partial/complete transaction of the Common Bile Duct, injury to the stomach, instrument failure and bilio-digestive fistula. We found the main reason for conversion to be failure of anatomical identification of Calot's triangle structures because of severe inflammation caused either by Acute Cholecystitis or by dense adhesions caused by recurrent attacks of cholecystitis leading to obscure anatomy. In our study port site wound infection occurred in $3 \%$ patients. This is consistent with international studies that show that incidence of surgical site infection (SSI) was significantly lower in laparoscopic surgery compared to open surgery and patients treated with laparoscopy were 72\% less likely to experience an SSI.12 Iatrogenic bile duct injury (IBDI) is one of the most feared complications associated with cholecystectomy. There was no case of IBDI in our patients. Although there is no consensus, most studies however show an increase in the incidence of these injuries. With the advent of laparoscopy, the rate of serious bile duct injuries after cholecystectomy had a 
discreet increase of up to $0.8 \%$, whilst the one related to the open route remained between $0.2-$ 0.3 percent. The prognosis is directly related to the patient's underlying conditions as well as the time elapsed between the lesion and its identification and treatment which is basically the reconstruction of the biliary path. The Roux-en-Y hepatico jejunostomy is considered to be the treatment of choice today. ${ }^{13}$

Laparoscopic cholecystectomy is now emerging as the procedure of choice in the management of patients admitted with Acute Cholecystitis. Single-centre and population-based studies documented the benefits of Laparoscopic cholecystectomy in the management of various gallbladder diseases, including Acute Cholecystitis. ${ }^{14,15}$ The $6 \%$ of our cases who presented with acute cholecystitis and who had no additional comorbidities were also treated with standard Laparoscopic cholecystectomy technique with exceptionally good results. Bleeding complications account for up to one third of all major complications seen in Laparoscopic cholecystectomy, and are the second most common cause of death (after anaesthesia related complications) in patients undergoing the procedure. ${ }^{16}$ The reported incidence of uncontrollable bleeding in Laparoscopic cholecystectomy can be up to $2 \%$ (reported range: $0.03-10 \%$ ). ${ }^{17}$ Fortunately we did not encounter any serious haemorrhagic complications. The incidence of Port Site Hernia (PSH) in a range of laparoscopic procedures has been described as between $0.14 \%$ and $22 \% .12$ In addition to pain, PSH can lead to severe complications, including bowel obstruction, strangulation, and perforation. ${ }^{9}$ However, in our study there has been no PSH reported. The three port approach gave the patients more satisfaction than with the four-port approach, especially in females for cosmetic reasons. 18 Various studi es have shown that 3-port Laparoscopic Cholecystectomy technique was not difficult to master and could be safely performed by trained personnel. 19-22

CONCLUSION: Three port LC has proven to be a safe procedure with multiple benefits to the patients, including reduced postoperative pain, good cosmesis, shorter hospital stay, shorter convalescence period, and decreased risk of selected complications compared with open cholecystectomy.We recommend that while separating gall bladder from its bed,dissection should be cautious without hurry and little towards liver side to avoid all bladder perforation.However one should not hesitate to open technique if any difficulty or doubt regarding anatomy arises. Proper training, careful case selection, good visual equipment, and very meticulous technique are the key factors that ensure good results.

\section{REFERENCES:}

1. McMahon AJ, Fischbacher CM, Frame SH, MacLeod MC. Impact of laparoscopic cholecystectomy: a population-based study. Lancet 2000; 356: 1632-7.

2. Shea JA, Berlin JA, Bachwich DR, Staroscik RN, Malet PF, McGuckin M, et al. Indications for and outcomes of cholecystectomy: a comparison of the pre and post laparoscopic eras. Ann Surg 1998; 227: 343-50.

3. Berggren U, Gordh T, Grama D, Haglund U, Rastad J, Arvidsson D. Laparo scopic versus open cholecystectomy: hospitalization sick leave, analgesia, and trauma responses. Br J Surg1994; 81: 1362-5.

4. Townsend CM Jr, Beauchamp RD, Evers M, et al, eds. Sabiston: Tratado de Cirurgia. A base biológica da práticacirúrgica moderna. 18ª ed. Philadelphia: Elsevier Saunders 2010; p. 1460. 
5. Bittner R. Laparoscopic Surgery: 15 years after clinical introduction. World J Surg 2006; 30: 1190-203.

6. Ros A, Gustafsson L, Krook H, Nordgren CE, Thorell A, Wallin G, et al. Laparoscopic cholecystectomy versus mini-laparotomy cholecystectomy: a prospective, randomized, single blinded study. Ann Surg 2001; 234: 741-9.

7. Sicklick JK, Camp MS, Lillemoe KD, Melton GB, Yeo CJ, Campbell KA, et al. Surgical management of bile duct injuries sustained during laparoscopic cholecystectomy: peri operative results in 200 patients. Ann Surg 2005; 241: 786-92; discussion 793-5.

8. Jacobi CA, Ordermann J, Zieren HU, Volk T. The impact of laparoscopy with carbon dioxide versus helium on local and systemic inflammation in an animal model of peritonitis. Surg Endosc 1998; 12:480.

9. Lee JH, Kim W. Strangulated small bowel hernia through the port site: A case report. World J Gastroenterol 2008; 14: 6881-3.

10. Simopoulos C, Botaitis S, Polychronidis A, Tripsianis G, Karayiannakis AJ. Risk factors for conversion of laparoscopic cholecystectomy to open cholecystectomy. Surg Endosc 2005; 19: 905-9.

11. Botaitis S, Polychronidis A, Pitiakoudis M, Perente S, Simopoulos C. Does gender affect laparoscopic cholecystectomy? Surg Laparosc Endosc 2008; 18: 157-61.

12. Varela JE, Wilson SE, Nguyen NT. Laparoscopic surgery significantly reduces surgical-site infections compared with open surgery. Surg Endosc 2010; 24(2):270-6.

13. Jablonska B, Lampe P. Iatrogenic bile duct injuries: etiology, diagnosis and management. World J Gastroenterol 2009; 15: 4097-104.

14. Csikesz N, Ricciardi R, Tseng JF, Shah SA. Current status of surgical management of acute cholecystitis in the United States. World J Surg 2008; 32: 2230-6.

15. Livingston EH, Rege RV. A nationwide study of conversion from laparoscopic to open cholecystectomy. Am J Surg 2004; 188: 205-11

16. Erol DD, Polat C, San O. The diagnosis and early treatment of acute hemorrhagic shock after laparoscopic cholecystectomy. Internet J Anaesthesia 2005;9

17. Schäfer M, Lauper M, Krähenbühl L. A nation’s experience `bleeding complications during laparoscopy. Am J Surg 2000; 180: 73-7

18. Osborne D,Boe B,Rosemurgy AS,Zervos EE-Am Surg 2005;71(4):298-302

19. Kang KJ, Lim TJ. Tip for microlaparoscopic cholecystectomy: easy removal of the gallbladder after laparoscopic cholecystectomy using the three-port technique. Surg Laparosc Endosc Percutan Tech. 2003;13(2):118 -120.

20. Lomanto D, De Angelis L, Ceci V, et al. Two-trocar laparoscopic cholecystectomy: a reproducible technique. Surg Laparosc Endosc Percutan Tech. 2001;11(4):248 -251.

21. Reardon PR, Kamelgard JI, Applebaum B, Rossman L, Bru nicardi FC. Feasibility of laparoscopic cholecystectomy with miniaturized instrumentation in 50 consecutive cases. World J Surg. 23(2):128 -131, 1999; discussion 131-132

22. Leggett PL, Churchman-Winn R, Miller G. Minimizing ports to improve laparoscopic cholecystectomy. Surg Endosc. 2000;14(1):32-3 


\section{Tables and figures:}

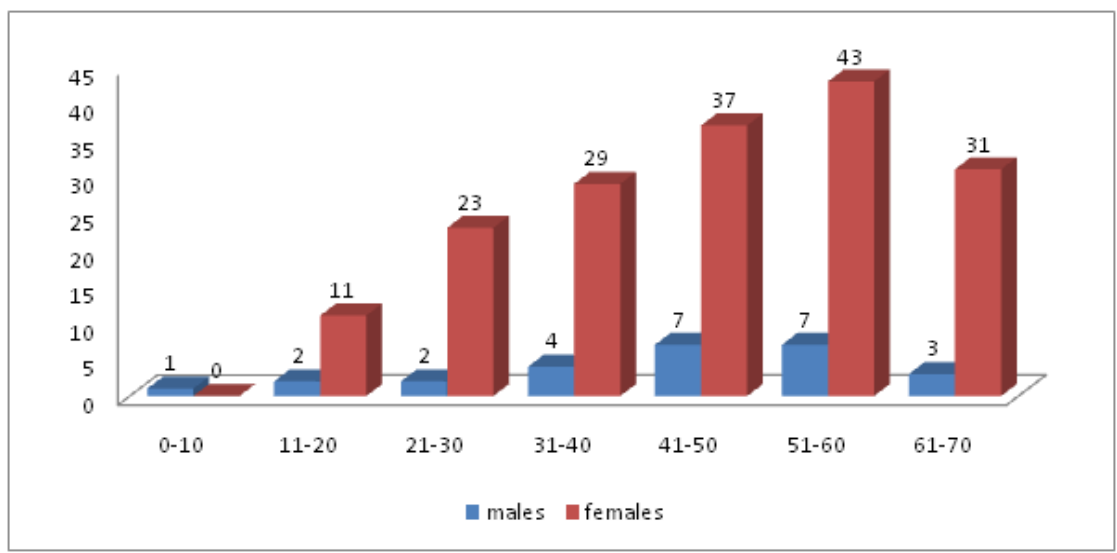

Figure no. 1: Sex and Age distribution of the Patients

\begin{tabular}{|c|c|c|}
\hline \multirow{2}{*}{ Indication of surgery } & \multicolumn{2}{|c|}{ Study Subjects } \\
\hline & No. & $\%$ \\
\hline Symptomatic cholelithiasis & 153 & 76.5 \\
\hline Chronic cholecystitis & 32 & 16 \\
\hline Acute cholecystitis & 12 & 6 \\
\hline Mucocele of gall bladder & 2 & 1 \\
\hline Polyp of gall bladder & 1 & 0.5 \\
\hline Total & 200 & 100 \\
\hline
\end{tabular}

\begin{tabular}{|c|c|c|}
\hline \multirow{2}{*}{ ASA classification } & \multicolumn{2}{|c|}{ Study Subjects } \\
\cline { 2 - 3 } & No. & $\%$ \\
\hline ASA1 & 60 & 30 \\
\hline ASA2 & 106 & 53 \\
\hline ASA3 & 34 & 17 \\
\hline Total & 200 & 100 \\
\hline \multicolumn{2}{|c|}{ Table 2: ASA classification } \\
\hline
\end{tabular}

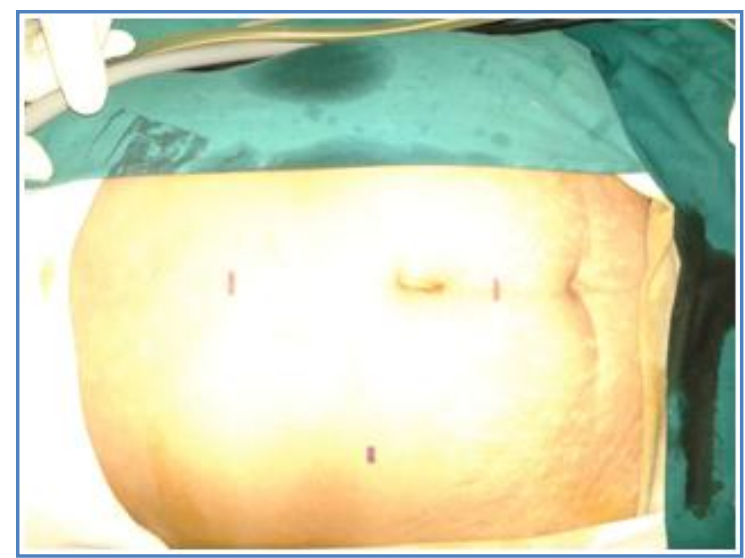

Image no.1: Port site marking

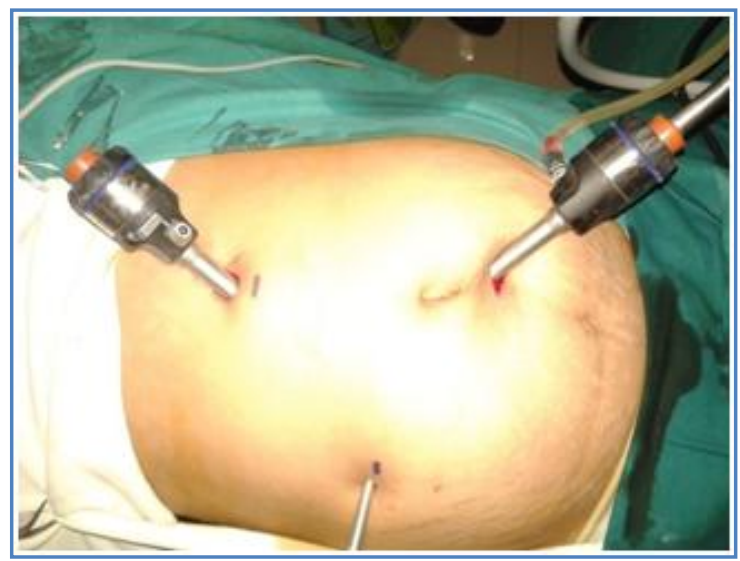

Image no.2: Port insertion 


\section{AUTHORS:}

1. Krishnanand

2. Roshan Chanchlani

3. Madhu Chanchlani

\section{PARTICULARS OF CONTRIBUTORS:}

1. Associate Professor, Department of Surgery, Chirayu Medical College and Hospital, Bhopal.

2. Associate Professor, Department of Surgery, Chirayu Medical College and Hospital, Bhopal.

3. Assistant Professor, Department of Ophthalmology, Chirayu Medical College and Hospital, Bhopal.

\section{NAME ADDRESS EMAIL ID OF THE} CORRESPONDING AUTHOR:

Dr. Roshan Chanchlani, 1/6 - Idgah Kothi, Doctors Enclave, Near Filter Plant, Idgah Hills,

Bhopal, (M.P.) - 462001.

Email - roshanchanchlani@gmail.com

Date of Submission: 17/10/2013.

Date of Peer Review: 18/10/2013.

Date of Acceptance: 22/10/2013.

Date of Publishing: 23/10/2013 